\title{
Management of cardiac arrest in a parturient with Eisenmenger's syndrome and complete atrioventricular block during Cesarean section -a case report-
}

\author{
Gaab Soo Kim, Mikyung Yang, Choo Hoon Chang, Eun Kyung Lee, and \\ Jeong Yeon Choi \\ Department of Anesthesiology and Pain Medicine, Samsung Medical Center, Sungkyunkwan University School of \\ Medicine, Seoul, Korea
}

\begin{abstract}
A 26-year-old parturient with Eisenmenger's syndrome and complete atrioventricular block was presented for emergency Cesarean section due to preterm labor. Ventricular tachycardia (VT), which progressed to ventricular fibrillation (VF), started immediately after the incision. Cardiopulmonary resuscitation with electric shocks was given by anesthesiologists while the obstetrician delivered the baby between the shocks. A cardiac surgeon was ready for extracorporeal membrane oxygenation institution in case of emergency but spontaneous circulation of the patient returned after the 3rd shock and the delivery of the baby. The newborn's Apgar score was 4 at 1 minute and 8 at 5 minutes. An implantable cardioverterdefibrillator was inserted before the discharge because the patient had recurrent episodes of VT and VF postoperatively.
\end{abstract}

Key Words: Atrioventricular block, Cardiopulmonary resuscitation, Cesarean section, Eisenmenger complex.

Eisenmenger's syndrome is an obstructive pulmonary vascular disease, which results from pre-existing cardiac defects with large left-to-right shunt. This increases pulmonary artery pressures and when this approaches to systemic levels, the direction

Corresponding author: Mikyung Yang, M.D.

Department of Anesthesiology and Pain Medicine, Samsung Medical Center, Sungkyunkwan University School of Medicine, 50, Irwondong, Gangnam-gu, Seoul 06351, Korea

Tel: 82-2-3410-2462, Fax: 82-2-3410-6626

E-mail: anesyang@skku.edu

Received: February 14, 2014.

Revised: 1st, April 1, 2014; 2nd, April 25, 2014.

Accepted: April 28, 2014.

Korean J Anesthesiol 2015 December 68(6): 617-621 http://dx.doi.org/10.4097/kjae.2015.68.6.617 of blood flow becomes bi-directional or right-to-left. Patients with Eisenmenger's syndrome are advised to avoid the pregnancy due to high maternal and fetal mortality [1]. There are several case reports on anesthetic management of patients with Eisenmenger's syndrome during Cesarean section [2-4]. However, the patient in this case was combined with complete atrioventricular block (AVB), which resulted in cardiac arrest before the delivery of the baby. Therefore, this is the first case to report a successful management of cardiac arrest in a parturient with Eisenmenger's syndrome combined with complete AVB.

\section{Case Report}

A 26-year-old woman $(41 \mathrm{~kg} / 155 \mathrm{~cm})$ with known Eisenmenger's syndrome due to patent ductus arteriosus (PDA) and

(c) This is an open-access article distributed under the terms of the Creative Commons Attribution Non-Commercial License (http://creativecommons.org/ licenses/by-nc/4.0/), which permits unrestricted non-commercial use, distribution, and reproduction in any medium, provided the original work is properly cited. 
ventricular septal defect (VSD) was referred to our hospital at $7^{\text {th }}$ week of gestation for further management of the pregnancy. Transthoracic echocardiography showed a large VSD of $3.9 \mathrm{~cm}$ diameter and a PDA of $0.6-0.7 \mathrm{~cm}$ diameter resulting in a leftto-right dominant bidirectional shunt flow. The left ventricle (LV) was severely enlarged and systolic function was normal with ejection fraction of $62 \%$. The right ventricle (RV) and pulmonary artery (PA) were also dilated and severe pulmonary hypertension was present with RV systolic pressure of $128 \mathrm{mmHg}$ and left atrium enlargement (LAE). An immediate therapeutic abortion was highly recommended because of high risk pregnancy, but the patient refused and showed a strong desire for the maintenance of the pregnancy. Sildenafil $20 \mathrm{mg}$ three times a day was prescribed and an elective induction of delivery was planned at $34-35^{\text {th }}$ week of gestation after regular follow up. During follow up, echocardiographic findings were aggravated [slightly increased mitral regurgitation (MR), tricuspid regurgitation (TR), left atrial volume index amount $<106 \mathrm{ml} / \mathrm{m}^{2} \rightarrow 179$ $\mathrm{ml} / \mathrm{m}^{2}>$ ], and the cardiac enzyme were increased (NTproBNP $493.4 \mathrm{pg} / \mathrm{ml} \rightarrow 860.0 \mathrm{pg} / \mathrm{ml}<$ reference range; $0-153 \mathrm{pg} / \mathrm{ml}>$ ). She was admitted to our hospital and began to receive a continuous intravenous (IV) infusion ( $3 \mathrm{ng} / \mathrm{kg} / \mathrm{min}$ ) of treprostinil, a vasodilator, to reduce pulmonary hypertension. The preterm uterine contraction started two days after admission $\left(33^{+1}\right.$ week of gestation), and the obstetrician tried to control the preterm labor with atosiban, a tocolytics. But the attempt failed and an emergency Cesarean section was decided. Preoperative chest antero-posterior view showed cardiomegaly with pulmonary hypertension, and $3^{\text {rd }}$ degree AVB, left ventricular hypertrophy, LAE, and intraventricular conduction delay were observed on electrocardiography. Preoperative arterial blood gas analysis (ABGA) findings were $\mathrm{pH}$ 7.48, $\mathrm{PaCO}_{2} 24.7 \mathrm{mmHg}, \mathrm{PaO}_{2} 74$ $\mathrm{mmHg}$, and $\mathrm{HCO}_{3}{ }^{-} 18 \mathrm{mmol} / \mathrm{L}$. Preoperative hemoglobin $(\mathrm{Hb})$ was $12.6 \mathrm{~g} / \mathrm{dl}$ and hematocrit was $36.4 \%$. Oxygen saturation $\left(\mathrm{SpO}_{2}\right)$ was maintained with $94-95 \%$ at $\mathrm{O}_{2} 1 \mathrm{~L}$ via nasal cannula. The blood pressure was 140-160/50-70 mmHg at ward, and heart rates were $30-50$ beats per minute (bpm). The patient gave her permission about the possibility of extracorporeal membrane oxygenation (ECMO) support in case of cardiac arrest.

On arrival at the operating room, the patient was on a continuous infusion of IV treprostinil $25 \mathrm{ng} / \mathrm{kg} / \mathrm{min}$ via peripherally inserted central catheter. Due to the complete AVB, the heart rates were 30-40 bpm. An external patch (adult/child multifunction defibrillation electrode pads, Philips, Andover, USA) was attached for intraoperative pacing or defibrillation. The patient was positioned at $15^{\circ}$ left tilt position using a right buttock wedge and an arterial line was cannulated in an awake state. Obstetrician, cardiac surgeon, perfusionist, and neonatologist stood by for emergency situation. Anesthesia was induced with etomidate $10 \mathrm{mg}$ and rocuronium $50 \mathrm{mg}$, and mask ventilation was performed with nitric oxide (NO) 20 ppm added in oxygen and sevoflurane (2 vol\%). Norepinephrine $0.02 \mu \mathrm{g} / \mathrm{kg} / \mathrm{min}$, isoproterenol $0.02 \mu \mathrm{g} / \mathrm{kg} / \mathrm{min}$, and milrinone $0.5 \mu \mathrm{g} / \mathrm{kg} / \mathrm{min}$ were infused continuously from the start of induction. After intubation, blood pressure was 140/40 mmHg, $\mathrm{HR}$ was $35 \mathrm{bpm}, \mathrm{SpO}_{2}$ was $100 \%$. Post-induction ABGA findings $\left(\mathrm{FIO}_{2}\right.$ 0.67, $\mathrm{ETCO}_{2} 25$ $\mathrm{mmHg}$ ) were $\mathrm{pH}$ 7.34, $\mathrm{PaCO}_{2} 25 \mathrm{mmHg}, \mathrm{PaO}_{2} 209 \mathrm{mmHg}$, and $\mathrm{HCO}_{3}{ }^{-} 13.2 \mathrm{mmol} / \mathrm{L}$. Anesthesia was maintained with sevoflurane and a continuous remifentanil infusion.

Immediately after incision, VT developed suddenly and synchronized direct current (DC) cardioversion shock (200 J) was given with a temporary interruption of operation. After shock, her rhythm changed into VF and defibrillation shock (200 J) was given again, but was not effective. IV Epinephrine $100 \mu \mathrm{g}$ was given and chest compression was started by an anesthesiologist. Obstetrician re-started the operation and cardiac surgeon prepared for the insertion of ECMO cannula under the rhythm of VF. Two minutes after, defibrillation shock (200 J) was given again and the baby was delivered shortly after the shock. Return of spontaneous circulation (ROSC) was obtained and blood pressure was normalized after the shock and baby-out. Ten minutes after induction, a female baby with $1.7 \mathrm{~kg}$ weight was delivered with Apgar scores of 4 at 1 minute and 8 at 5 minutes. Even though the baby's initial crying was weak and the skin color was pale, her crying and skin color rapidly improved after mask bagging with $\mathrm{O}_{2} 5 \mathrm{~L}$ without intubation. The cord $\mathrm{pH}$ was 7.32 and the newborn was transferred to the neonatal intensive care unit (ICU) for further management. Oxytocin was not administered after the delivery of the baby and the placenta in order to prevent aggravation of RV failure and pulmonary hypertension. A rectal suppository of misoprostol $200 \mu \mathrm{g} 4 \mathrm{EA}$ was used for uterine contraction instead. $\mathrm{NaHCO}_{3} 40 \mathrm{mEq}$ was slowly infused after ROSC. At the end of operation, ABGA findings $\left(\mathrm{FIO}_{2} 0.37\right.$, $\mathrm{ETCO}_{2} 30$ ) were $\mathrm{pH} 7.32, \mathrm{PaCO}_{2} 31 \mathrm{mmHg}, \mathrm{PaO}_{2} 83.5 \mathrm{mmHg}$, and $\mathrm{HCO}_{3}^{-} 15.6 \mathrm{mmol} / \mathrm{L}$ and $\mathrm{Hb}$ was $10.5 \mathrm{~g} / \mathrm{dl}$. The total anesthesia time was 78 minutes and the operation time was 35 minutes. Total input/output was described as below: crystalloid 1,100 $\mathrm{ml}$, hydroxyethyl starch $500 \mathrm{ml}$, urine output $200 \mathrm{ml}$, estimated blood loss $500 \mathrm{ml}$. The patient was then transferred to the coronary care unit and received mechanical ventilation with NO 20 ppm inhalation and a continuous infusion of remifentanil 0.02 $\mu \mathrm{g} / \mathrm{kg} / \mathrm{min}$ and with treprostinil $8 \mathrm{ng} / \mathrm{kg} / \mathrm{min}$.

On postoperative day (POD) 1, NO was stopped and the patient was extubated but showed hemoptysis for several times. As prophylactic antibiotics, cefuroxime $0.75 \mathrm{~g}$ was IV given three times a day for 4 days. On POD 3, the patient received red blood cell transfusion due to anemia ( $\mathrm{Hb} 8.2 \mathrm{~g} / \mathrm{dl}$ ) and a continuous infusion with furosemide to maintain negative fluid balance with a target body weight of 39-40 kg to decrease pulmonary edema and improve dyspnea. On POD 7, her chest computed 
tomography (CT) showed diffuse alveolar hemorrhage (Fig. 1). The patient complained about insomnia and depressive mood, and so she was transferred to the sub-ICU after psychological consultation. Immediately after moving to the sub-ICU bed, her eyeballs were deviated and she became pulseless, and CPR was started. During 2 cycles of CPR, $500 \mathrm{ml}$ normal saline was rapidly dripped and $2 \mathrm{mg}$ epinephrine was given. Then the electrocardiogram monitoring revealed VF. Defibrillation shock was given and ROSC was obtained after another 1 cycle of CPR, and she was transferred to the ICU again. On POD 8, the patient showed Torsades de Points type VT (Fig. 2), pulseless VT, and eyeball deviation, and an electric shock was given. $\mathrm{K}^{+}$and $\mathrm{Mg}^{++}$were replaced for the maintenance of high normal ranges to prevent fatal arrhythmia, but repetitive VT with basal rhythm of complete AVB occurred, and so the patient received DC shocks more than 30 times. A transient pacemaker was inserted and maintained over-pacing of the heart rate at $100 \mathrm{bpm}$. On POD 9, the transient pacemaker rate was reduced to $60 \mathrm{bpm}$ and then was removed at POD 12. On POD 12, lung sonography showed post-CPR lung contusion or alveolar hemorrhagic consolidation. In spite of aggressive treatment, her dyspnea has

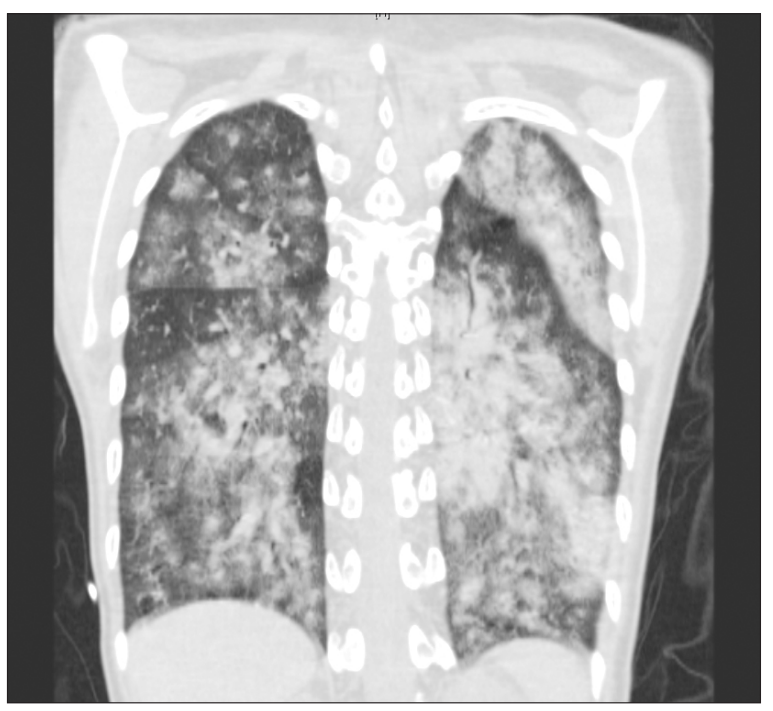

Fig. 1. There are extensive centrilobular consolidation and ground-glass opacity on both lungs which imply diffuse alveolar hemorrhage. not improved (WHO functional class IV), so IV treprostinil was increased up to $18 \mathrm{ng} / \mathrm{kg} / \mathrm{min}$ and oral $62.5 \mathrm{mg}$ bosentan, an endothelin receptor antagonist, twice a day was added. On POD 18 , she was transferred to the general ward, and an implantable cardioverter-defibrillator (ICD) was inserted on POD 19. The patient showed persistent anemia despite negative stool occult blood test and intermittent transfusion, and was presumed to have anemia of chronic disease with severe iron deficiency $(\mathrm{Hb}$ $7.4 \mathrm{~g} / \mathrm{dl}$ ). Chest CT showed resolving diffuse alveolar hemorrhage and combined pneumonia on POD 25. On POD 26, IV treatment with treprostinil was changed into subcutaneous form with $20 \mathrm{ng}$ and warfarin was started with a target aPTT of 45$70 \mathrm{sec}$. Heparin therapy was initiated on POD 8 and stopped on POD 35. On POD 32, ferric hydroxide sucrose $400 \mathrm{mg}$ was IV given to replace iron and the patient's $\mathrm{Hb}$ level was $8.4 \mathrm{~g} / \mathrm{dl}$ with a target of 14-15 g/dl just before discharge. The patient was discharged with home $\mathrm{O}_{2}$, subcutaneous treprostinil $22 \mathrm{ng}$, and warfarin $4 \mathrm{mg}$ on POD 37.

\section{Discussion}

Our patient had been coming to our hospital for regular check-up and management since the early pregnancy. Therefore, her emergency Cesarean section could be performed under the supervision of a multidisciplinary experienced team including an obstetrician, anesthesiologists, a cardiac surgeon, a perfusionist, and a neonatologist. The patient had a complete AVB, but a transient pacemaker was not preoperatively inserted because of the risk of systemic embolization through VSD and PDA. General anesthesia was selected for this case because the chance of cardiac failure or arrest and the need for pacing, electric shock, or ECMO support were high due to underlying complete heart block. Advantages of regional anesthesia were reducing the risk of venous embolism and providing postoperative analgesia. Disadvantages of regional anesthesia were the possibility of increasing the amount of right-to-left shunt by sympathetic block and decrease in systemic vascular resistance (SVR) and less controllability in case of arrest. Disadvantages of general anesthesia were the possibility of acute rising of pulmonary vascular resistance (PVR) during intubation and reduced venous return because of positive pressure ventilation [3].

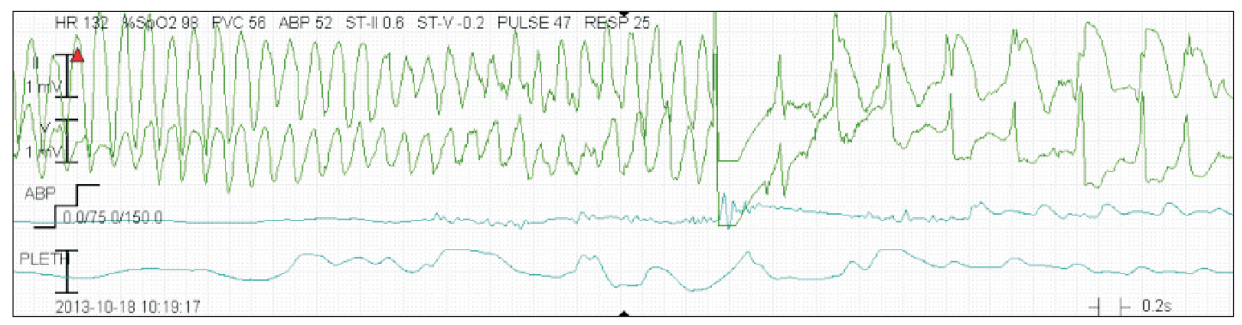

Fig. 2. Electrocardiogram strip shows Torsades de Pointes type ventricular tachycardia and its termination with a cardioversion shock. 
For the anesthetic management of patients with Eisenmenger's syndrome, it is important to minimize the increment of PVR and decrement of SVR, to avoid hypovolemia, and to preserve cardiac contractility in order to avoid hypoxemia and right heart failure. To achieve this goal, we prepared NO inhalation and a continuous infusion of milrinone to reduce PVR, norepinephrine to maintain SVR, and hydroxyethyl starch infusion to compensate volume loss.

Patients with Eisenmenger's syndrome present with high PVR associated with pulmonary hypertension at or near the systemic values with a reversed or bidirectional shunt. In our case, the patient had a bidirectional shunt with a left-to-right shunt dominant state. Therefore, she did not show profound hypoxemia as described in other reports [2-5]. An excessive decrease in PVR compared to SVR causes temporary high oxygen saturation in case of bidirectional shunt, but can eventually result in decreased systemic perfusion leading to systemic hypotension and acidosis. Therefore, it is very important to control the relative ratio of right-to-left or left-to-right shunt. During induction, a high $\mathrm{FIO}_{2}$ of 1.0 was used to prevent an acute rise of PVR. After baby was out and after confirmation of adequate oxygenation, $\mathrm{FIO}_{2}$ was decreased to 0.6. However, the diastolic pressure was maintained at $40 \mathrm{mmHg}$, which might imply an inadequate left side stroke volume due to an increased left-to-right shunt. Since $\mathrm{SpO}_{2}$ was well maintained at $\mathrm{FIO}_{2}$ 0.6, we reduced $\mathrm{FIO}_{2}$ further to 0.4 to counterbalance the amount of left-to-right shunt by slightly increasing PVR.

A PA catheter was not inserted in this case because the risk of arrhythmia, pulmonary artery rupture or provoking pulmonary hypertensive crisis might be greater than the benefit of the evaluation of hemodynamic status and the severity of shunt flow. Moreover, its proper placement may have not been easy [2, 5] and its information may not reflect the actual hemodynamic status because of the large VSD. Patients with Eisenmenger's syndrome due to ASD or PDA will benefit from PA catheter monitoring because it can monitor pressure gradients between right and left circulations. However, in patients with Eisenmenger's syndrome due to VSD, it is impossible to monitor the intraventricular pressure gradients between right and left ventricles. Systemic arterial saturations are related to the amount of right-to-left shunt. $\mathrm{SpO}_{2}$ will decrease if the right-to-left shunt increases because of an increased PVR or decreased SVR. Use of pulse oximetry could be a safer and better method of determining the degree of right-to-left shunt flow in these patients [6].

In this case, the complete AVB might have been the triggering factor for the arrhythmia. Previously, a cardiac arrest from Torsades de Points was reported in a patient with complete heart block (the "R-on-T" phenomenon) [7]. The complete heart block was associated with an atrioventricular septal defect and could precipitate Torsades de Points and arrest through QT prolongation. Women appear to be more susceptible than men [8]. To prevent sudden death, pacemaker insertion and ICD implantation were advocated [9]. The patient in this case had a large VSD and a complete AVB preoperatively, developed VT/ VF intraoperatively, sustained repetitive Torsades de Points type VT and VF postoperatively, and was treated with a transient pacemaker insertion followed by an ICD implantation. Therefore, it is reasonable to presume the complete AVB as the cause of arrhythmia in this case.

Isoproterenol was continuously infused because of complete AVB, but it was stopped after VT and VF. However, isoproterenol can be used for the treatment of idiopathic recurrent VF if the induction mechanism of VF is associated with enhanced vagal tone rather than with enhanced sympathetic activity. Mittadodla et al. [10] reported a VF storm could be effectively treated by increasing heart rate with isoproterenol or overdrive pacing in a pregnant woman not responding to traditional antiarrhythmic therapy.

Congestive heart failure followed by pregnancy is the most common cause of death in patients with Eisenmenger's syndrome. In many reports, cardiac failures occurred shortly after the delivery of the fetus and blood loss [2-4], which caused hypovolemia, decrease in SVR, increase in PVR, and severe hypoxemia: were usually treated with volume replacement, vasopressor, and NO inhalation. However, this patient developed sudden VT immediately after the incision and then progressed to VF and returned to ROSC after delivery. Even though the total arrest time was 2 minutes, if it had lasted longer it could have been fatal to both the mother and the baby. Several studies reported that the ROSC did not occur until the uterus was emptied by a perimortem Cesarean section [11] and suggested perimortem Cesarean section might be regarded as one treatment option when all other resuscitation methods fail. However, perimortem Cesarean section is rarely done within 5 minutes to optimize maternal salvage from cardiac arrest $[12,13]$. In our case, the patient received perimortem Cesarean section and resuscitation simultaneously. Cesarean section was interrupted three times because of the electric shocks. Transthoracic impedance was not significantly altered during pregnancy [13]. Therefore, usual defibrillation dosages can be applied to a parturient. Chest compressions in a left lateral tilt from the horizontal are feasible but less forceful compared to the supine position and manual leftward displacement of the gravid uterus was preferred to lateral tilt during maternal resuscitation [14].

Was the electric shock given to the mother harmful to the baby? After the review of 44 case reports of electrical cardioversion during pregnancy, Tromp et al. [15] concluded that it was a highly effective procedure and assumed it as safe for both, the mother and the baby. However, there were two cases of fetal distress directly after the cardioversion, necessitating an immediate 
Cesarean section at 37 th and 28th week of gestational age. Even though both neonates of the above cases were born healthy, facilities for fetal monitoring and emergency Cesarean section should be available when an electrical cardioversion is planned. The intensity and the pathway of the current are important in case of electric shock. Therefore, it is necessary to place the patch properly away from the uterus.

Was the ROSC obtained from the CPR or the delivery? Several studies report that the delivery itself can terminate the VF. Therefore, delivery should not be delayed in case of cardiac arrest in patients with Eisenmenger's syndrome because it can guarantee the safety of the fetus and the mother simultaneously. To wait for a moment for defibrillation can be permitted. On the other side, it could be insisted that the ROSC was the result of effective defibrillation and proper CPR because this patient suffered repetitive VT/VF postoperatively and successfully recovered after electric shock each time.
Patients with Eisenmenger's syndrome should be closely monitored in the ICU after delivery because they are vulnerable to heart failure, arrhythmia, and severe hypoxemia in this period. Our patient also suffered from fatal arrhythmias, diffuse alveolar hemorrhage, anemia, and congestive heart failure.

In conclusion, the anesthetic management of a parturient with Eisenmenger's syndrome should be focused on controlling the relative ratio of the bidirectional shunt by avoiding the increase in PVR and decrease in SVR. In patients with complete $\mathrm{AVB}$, preoperative insertion of a transient pacemaker is recommended because they have a high risk of developing cardiac arrest from Torsades de Points type VT. When a parturient suffers sudden cardiac arrest during Cesarean section, a high quality CPR and perimortem Cesarean section should be simultaneously performed without delay for the safety of the mother and the baby.

\section{References}

1. Drenthen W, Pieper PG, Roos-Hesselink JW, van Lottum WA, Voors AA, Mulder BJ, et al. Outcome of pregnancy in women with congenital heart disease. J Am Coll Cardiol 2007; 49: 2303-11.

2. Lee SY, Ko JS, Jung JW, Lee SM, Kang IS, Park SW, et al. Perioperative management of a parturient with Eisenmenger's syndrome undergoing Cesarean section. Anesth Pain Med 2007; 2: 246-51.

3. Lee BJ. Anesthesia for Cesarean section in a parturient patient with Eisenmenger's syndrome. Anesth Pain Med 2006; 1: 116-9.

4. Hwang BM, Sim JY, Cho SK, Lee DM. Epidural Anesthesia for Cesarean section in parturient with Eisenmenger's syndrome. Korean J Anesthesiol 2000; 38: 563-6.

5. Chung KH, Kim SH, Chun DH, Lee JY, Park SC, Park CH, et al. Anesthetic management for emergent craniotomy in a patient with Eisenmenger's syndrome. Korean J Anestheiol 2009; 57: 666-9.

6. Devitt JH, Noble WH, Byrick RJ. A Swan-Ganz catheter related complication in a patient with Eisenmenger's syndrome. Anesthesiology 1982; 57: 335-7.

7. Nguyen AP, Sarmast SA, Kowal RC, Schussler JM. Cardiac arrest due to torsades de pointes in a patient with complete heart block: the "R-on-T" phenomenon. Proc (Bayl Univ Med Cent) 2010; 23: 361-2.

8. Nijjer S, White S, Gatzoulis MA. Torsades de Pointes in atrioventricular septal defect. Int J Cardiol 2009; 134: e51-2.

9. Wilmin S, De Bels D, Knecht S, Gottignies P, Gazagnes MD, Devriendt J. Torsade de pointes in Kearns-Sayre syndrome. Pract Neurol 2012; 12: 199-201.

10. Mittadodla PS, Salen PN, Traub DM. Isoproterenol as an adjunct for treatment of idiopathic ventricular fibrillation storm in a pregnant woman. Am J Emerg Med 2012; 30: 251.e3-5.

11. Katz V, Balderston K, DeFreest M. Perimortem cesarean delivery: were our assumptions correct? Am J Obstet Gynecol 2005; 192: 1916-20.

12. Dijkman A, Huisman CM, Smit M, Schutte JM, Zwart JJ, van Roosmalen JJ, et al. Cardiac arrest in pregnancy: increasing use of perimortem caesarean section due to emergency skills training? BJOG 2010; 117: 282-7.

13. Jeejeebhoy FM, Zelop CM, Windrim R, Carvalho JC, Dorian P, Morrison LJ. Management of cardiac arrest in pregnancy: a systematic review. Resuscitation 2011; 82: 801-9.

14. Kundra P, Khanna S, Habeebullah S, Ravishankar M. Manual displacement of the uterus during Cesarean section. Anaesthesia 2007; 62: 460-5.

15. Tromp CH, Nanne AC, Pernet PJ, Tukkie R, Bolte AC. Electrical cardioversion during pregnancy : safe or not? Neth Heart J 2011; 19 : 134-6. 